Research Article

\title{
A Study of Phenomena of Shame and Social Comparison in Depressive Disorders
}

\author{
Abhilasha Yadav', Pradeep Sharma ${ }^{2}$, Arvin Kamra $^{3}$ \\ ${ }^{1}$ Professor, Department of Psychiatry, VMMC \& Safdarjung Hospital, New Delhi, India. \\ ${ }^{2}$ Professor, Psychiatric Centre Jaipur, Jaipur, Rajasthan. \\ ${ }^{3}$ Consultant Psychiatrist, Brain and Behaviour Clinic, Delhi, India. \\ DOI: https://doi.org/10.24321/2581.5822.201910
}

I $\quad \begin{array}{lllll}\mathbf{N} & \mathbf{F} & \mathbf{O}\end{array}$

\section{Corresponding Author:}

Abhilasha Yadav, Professor, Department of Psychiatry, VMMC \& Safdarjung Hospital, New Delhi, India.

E-mail Id:

kamra.abhilasha@gmail.com

Orcid Id:

https://orcid.org/0000-0002-9044-5366

How to cite this article:

Yadav A, Sharma P, Kamra A. A Study of Phenomena of Shame and Social Comparison in Depressive Disorders. J Adv Res Psychol Psychother 2019; 2(3\&4): 4-10.

Date of Submission: 2020-01-25

Date of Acceptance: 2020-03-19

\section{$\begin{array}{llllllll}\mathbf{A} & \mathbf{B} & \mathbf{S} & \mathbf{T} & \mathbf{R} & \mathbf{A} & \mathbf{C} & \mathbf{T}\end{array}$}

Background: The phenomena of shame and social comparison and their association with psychopathology especially with depression has been studied extensively in western countries but there is a dearth of research on this subject in Indian setting.

Aim \& Objectives: To explore the phenomena of shame and social comparison and its correlation with depression.

Materials and Methods: This study was conducted at Psychiatric Centre Jaipur (SMS Medical College, Jaipur) on OPD basis from July 1998 to December 1999. This was a case control study, 50 matched subjects with age range $15-60$ years were included in study and control group. Study Group consisted of 50 depressed patients as per ICD-10 criteria (F32 and F33), controls were selected from general population randomly and were free from any psychiatric illness. Beck depression inventory, The Other as Shamer Scale, Social Comparison Scale were used in the study.

Statistical Analysis: Mean, Standard deviation, Student ' $\mathrm{t}$ ' test, Pearson's correlation co-efficient were used to analyse the data.

Result: Mean OAS score of study group was 27.08 and of control group 6.62 , and the difference between these scores in both the group was found to be statistically significant. A positive correlation was found between depression BDI scores and OAS scores for study group at $r=+0.7033$. There was an inverse correlation between depression BDI scores and social comparison rating scores for study group at $r=-0.2726$.

Conclusion: Shame and social comparison are found to be important variables in the phenomenology of depression. However, further research investigating the relationship between shame, social comparison and depression is needed, to support the findings of this study in Indian depressives.

Keywords: Depression, Shame, Social Comparison, Social Rank Theory, India 


\section{Introduction}

Shame is one of the self-conscious emotions, which has received much less attention in the clinical research literature. One of the most influential theorists who described the phenomenology of shame was Helen Block Lewis, ${ }^{1,2}$ she proposed that shame involves a sense of scrutiny and negative evaluation by a more powerful other (s). This leads to feelings of inferiority, helplessness, anger and self-consciousness. Lewis ${ }^{3}$ argued that shame refers to a collection of "affective cognitive states" in which embarrassment, mortification, humiliation, feeling ridiculed, chagrin, disgrace and shyness are among the variants.

An evolutionary model of shame also views shame as related to power and status conflicts, that is, shame is concerned with dominance and subordination (SuperiorInferior). ${ }^{4,5}$ Thus, shame as a response to a real or imagined audience (who negatively evaluate the self) is central to both the evolutionary theory and Lewis's theory.

Theoretical model of self-conscious emotions by Tracy and Robbins describes major features of self-conscious emotions which are, 1) Self-conscious emotions require self-awareness and self-representations, 2) Self-conscious emotions emerge later in childhood than basic emotions, 3) Self-conscious emotions facilitate the attainment of complex social goals, 4) Self-conscious emotions do not have discrete, universally recognized facial expressions, 5) Self-conscious emotions are cognitively complex. ${ }^{6}$

A distinction must be made between shame as an emotional state, and shame-proneness as an emotional trait or disposition to experience shame. ${ }^{7}$ Also, some authors argue that shame can be best conceptualized in terms of two dimensions: internal shame (being focused on negative self-evaluation) and external shame (being focused on fear of others' judgments). ${ }^{8}$

Various researchers have reported that specific psychopathologies, such as depression have been correlated with shame. ${ }^{5,9,10,11,12,13,14}$ In a study of undergraduates shame accounted for a substantial percentage of the variance in depression even after controlling for attributional style. ${ }^{15}$

The word depression, derived from the Latin word "Deprimere", means pressing down and being brought down in status or fortune. ${ }^{16}$ Festinger highlighted social comparison as a key variable in social relating and developed the first comprehensive theory of social comparison, which describes the process by which individuals utilize social information to evaluate their own abilities and options. ${ }^{17}$

Price's evolutionary theory suggests that those who judge themselves to be inferior to others, and vulnerable to being shamed, may be more likely to act submissively and feel inhibited in certain social situations in comparison to others who judge themselves to be equal or superior to others. ${ }^{18}$
Swallow and Kuiper in a major review found unfavourable social comparison to be a salient factor in depression. ${ }^{19}$ Carver and Ganellen suggested that depressed individuals tend to generalize a single failure (e.g., an unfavourable social comparison) to a pervasive negative view of self (i.e., general inferiority)..$^{20}$ Beck et al refer this pattern as the cognitive distortion of over generalization, typical of depression. ${ }^{21}$

\section{Aim \& Objectives}

- To study the role of phenomena of self-conscious emotions i.e. "shame" and social comparison in depression.

- To study the correlation of these phenomena with depression.

\section{Materials and Methods}

This study was conducted at Psychiatric Centre Jaipur (SMS Medical College, Jaipur) on OPD basis from July 1998 to December 1999. This was a case control study, 50 subjects each were included in study and control group.

\section{Study Group}

It consisted of 50 depressed patients attending the Psychiatric centre OPD and Psychiatry OPD of SMS Medical College, Jaipur. Patient of both the sex with age range 1560 , having diagnosis of depression as per ICD-10 criteria ( $F 32$ and $F 33$ ) were recruited in the study. Patients with other major mental illness, organic or medical conditions were excluded.

\section{Control Group}

Controls were selected from general population randomly or relatives of the patients attending the Psychiatric Centre, Jaipur and were free from any psychiatric illness. Controls were matched on age, sex, and other socio-demographic profile.

\section{Tools Used for the Study}

\section{Beck's Depression Inventory (BDI)}

$B D I$ created by Beck AT, ${ }^{22}$ is a 21 item self-report inventory, one of the most widely used psychometric test for measuring the severity of depression. BDI's internal consistency estimates yielded a mean coefficient alpha of 0.86 for psychiatric patients and 0.81 for nonpsychiatric subjects. In the present study, Hindi adaptation by Lal et al. (1974) was used.

\section{The Other as Shamer Scale (OAS)}

The scale is most currently used for measuring external shame ( Allan, Gilbert, and Goss 1994), ${ }^{23}$ it was developed from Internal Shame Scale (ISS) (1996). Thus, the focus of the OAS is on beliefs about how "others see or judge the self." 
This is an 18-item, self-report questionnaire. The OAS asks subjects to rate on a five-point scale (never, seldom, sometimes, frequently, almost always), a total OAS score is calculated by summing item scores. All inter-item correlations of OAS scale were positive and significant at the 0.05 level.

\section{Social Comparison Scale}

This is an 11-item scale developed by Allan and Gilbert (1995), ${ }^{24}$ which taps global comparisons to others in the domains of attractiveness, rank and group fit (feeling similar or different to others). The scale utilizes a semantic differential methodology whereby participants respond on a scale of 1 to 10, for example: "In relation to others I generally feel":

- Incompetent 12345678910 Competent

- The total Cronbach alpha reported by Allan and Gilbert (1995) was 0.91.

For the present study OAS and social comparison scales were translated into Hindi by three bilingual psychiatrists at Psychiatric Centre Jaipur and verified with other senior consultants to maximize conceptual clarity. Acceptable translation-retranslation reliability was established.

Data generated from the application of aforesaid scales was placed in tabular forms and the following statistical methods were used to analyse the findings.

\section{Statistical Analysis}

Mean, Standard deviation, Student ' $\mathrm{t}$ ' test, Pearson's correlation co-efficient were used to analyse the data.

\section{Ethical Issues}

Informed consent was obtained from each patient and control person prior to inclusion into the study.

\section{Result}

The present study was undertaken to explore the role of phenomena of shame and social comparison in depression. The study was hospital-based case-control study, done on Out-Patient Depressives. Both the groups were matched on age, sex, and other sociodemographic variables, this eliminated the chance of these variables confounding the scores of shame and social comparison. The mean age of the patients in the study group was 33.2 (S.D. $=10.98$ ) years and in the control group it was 33.1 (S.D. $=11.2$ ) years with age range $15-60$ years. Most of the subjects $(90 \%)$ were in age group 15-30 and 31-45 years. Majority of the patients were Hindu, married, from urban setting in and around Jaipur (Table 1 ). Only $12 \%$ study cases had mild depression, $28 \%$ had moderate depression and $60 \%$ had severe depression (Table 2). Mean BDI scores in study group was 27.08 with standard deviation of 9.46 (Table 3).
Table I. Socio-demographic profile: Study group Vs Control group

\begin{tabular}{|c|c|c|c|c|}
\hline & \multicolumn{2}{|c|}{$\begin{array}{l}\text { Study Group } \\
\qquad(\mathrm{N}=50)\end{array}$} & \multicolumn{2}{|c|}{$\begin{array}{l}\text { Control Group } \\
(\mathrm{N}=50)\end{array}$} \\
\hline \multicolumn{5}{|l|}{ Age (Years) } \\
\hline $15-30$ & 23 & \multirow{3}{*}{$\begin{array}{c}\text { Mean }=33.2 \\
S D=10.98\end{array}$} & 22 & \multirow{3}{*}{$\begin{array}{c}\text { Mean=33.1 } \\
S D=11.2\end{array}$} \\
\hline $31-45$ & 22 & & 21 & \\
\hline $46-60$ & 5 & & 7 & \\
\hline \multicolumn{5}{|l|}{ Sex } \\
\hline Male & & 36 & & 36 \\
\hline Female & & 14 & & 14 \\
\hline \multicolumn{5}{|l|}{ Religion } \\
\hline Hindu & & 46 & & 45 \\
\hline Muslim & & 4 & & 5 \\
\hline \multicolumn{5}{|l|}{ Occupation } \\
\hline Business & & 5 & & 7 \\
\hline Labour & & 5 & & 5 \\
\hline Service & & 21 & & 20 \\
\hline Housewife & & 11 & & 9 \\
\hline Student & & 5 & & 6 \\
\hline Professional & & 3 & & 3 \\
\hline \multicolumn{5}{|l|}{ Domicile } \\
\hline Rural & & 10 & & 11 \\
\hline Urban & & 40 & & 39 \\
\hline \multicolumn{5}{|l|}{$\begin{array}{c}\text { Educational } \\
\text { Status }\end{array}$} \\
\hline Primary & & 6 & & 6 \\
\hline Middle & & 8 & & 7 \\
\hline Secondary & & 18 & & 19 \\
\hline Graduation & & 17 & & 16 \\
\hline Postgraduation & & 1 & & 2 \\
\hline \multicolumn{5}{|l|}{$\begin{array}{l}\text { Type of } \\
\text { Family }\end{array}$} \\
\hline Joint & & 20 & & 22 \\
\hline Nuclear & & 30 & & 28 \\
\hline \multicolumn{5}{|l|}{ Marital Status } \\
\hline Married & & 31 & & 32 \\
\hline Single & & 13 & & 14 \\
\hline $\begin{array}{l}\text { Widow/ } \\
\text { Widower/ } \\
\text { Separated/ } \\
\text { Divorced }\end{array}$ & & 6 & & 4 \\
\hline
\end{tabular}


Table 2.Depression severity in study group $(\mathbf{N}=\mathbf{5 0})$

\begin{tabular}{|c|c|c|}
\hline Depression (BDI Score) & N & Percentage \\
\hline Mild (10-15) & 6 & 12 \\
\hline Moderate (16-23) & 14 & 28 \\
\hline Severe (>24) & 30 & 60 \\
\hline
\end{tabular}

Table 3.Mean BDI scores in study group

\begin{tabular}{|c|c|}
\hline Mean & S.D. \\
\hline 27.08 & 9.46 \\
\hline
\end{tabular}

Table 4.Mean OAS Score

\begin{tabular}{|c|c|c|c|}
\hline & $\begin{array}{c}\text { Study } \\
\text { Group } \\
(\mathbf{N}=50)\end{array}$ & $\begin{array}{c}\text { Control } \\
\text { Group } \\
(\mathbf{N}=50)\end{array}$ & \multirow{2}{*}{ t-value $=\mathbf{1 0 . 5 4 4}$} \\
pvalue $=<\mathbf{0 . 0 5}(\mathbf{s})$ \\
Mean & 27.08 & 6.62 & \multirow{2}{}{} \\
\cline { 1 - 3 } S.D. & 12.391 & 5.889 & \\
\hline
\end{tabular}

Table 5.Correlation between BDI scores and OAS Scores for study group (50)

\begin{tabular}{|c|c|c|}
\hline BDI Scores & OAS Scores & \\
\hline Mean $=27.08$ & Mean=27.08 & $r=+0.7033$ \\
SD $=9.46$ & SD $=12.391$ & \\
\hline
\end{tabular}

Mean OAS score of study group was 27.08 and of control group 6.62, and the difference between these scores in both the group was found to be statistically significant (Table 4). A positive correlation was found between depression BDI scores and OAS scores for study group at $r=+0.7033$ (Table 5).

In age subgroup, difference in mean OAS scores between study and control group was found statistically significant in all three age groups (Table 6). The difference between mean OAS scores in study and control group both in male and female was also found to be statistically significant (Table 7). In religion subgroup the difference between mean OAS scores in study and control group was found statistically significant in all religious groups (Table 8).

The difference between mean OAS scores in study and control group in both rural and urban area was found to be statistically significant (Table 9).

In occupational subgroup the difference between mean OAS scores in study and control group was found to be statistically significant in all the subgroup except in Professional group (Table 10). In educational subgroup the difference between mean OAS scores in study and control group was found statistically significant in all subcategories (Table 11).

Table 6.OAS-Age Sub-Group

\begin{tabular}{|c|c|c|c|c|c|c|}
\hline \multirow{2}{*}{ Age (Years) } & \multicolumn{2}{|c|}{ Study Group } & \multicolumn{2}{c|}{ Control Group } & \multirow{2}{*}{ 't'-value } & \multirow{2}{*}{ p-value } \\
\cline { 2 - 6 } & Mean & S.D. & Mean & S.D. & & \\
\hline $15-30$ & 27.37 & 13.55 & 6.909 & 7.144 & 6.481 & $<0.05(\mathrm{~s})$ \\
\hline $31-45$ & 27.380 & 12.318 & 5.095 & 4.06 & 7.873 & $<0.05(\mathrm{~s})$ \\
\hline $46-60$ & 24.4 & 7.503 & 10.285 & 5.056 & 3.654 & $<0.05(\mathrm{~s})$ \\
\hline
\end{tabular}

Table 7.OAS-Sex Sub-Group

\begin{tabular}{|c|c|c|c|c|c|c|}
\hline \multirow{2}{*}{ Sex } & \multicolumn{2}{|c|}{ Study Group } & \multicolumn{2}{c|}{ Control Group } & \multirow{2}{*}{ 't'-value } & \multirow{2}{*}{ p-value } \\
\cline { 2 - 6 } & Mean & S.D. & Mean & S.D. & & $<$ \\
\hline Male & 29.02 & 11.47 & 7.083 & 6.063 & 10.03 & $<0.05(\mathrm{~s})$ \\
\hline Female & 23.64 & 14.59 & 5.428 & 5.445 & 4.235 & $<0.05(\mathrm{~s})$ \\
\hline
\end{tabular}

Table 8.OAS-Religion Sub-Group

\begin{tabular}{|c|c|c|c|c|c|c|}
\hline \multirow{2}{*}{ Religion } & \multicolumn{2}{|c|}{ Study Group } & \multicolumn{2}{c|}{ Control Group } & \multirow{2}{*}{ 't'-value } & \multirow{2}{*}{ p-value } \\
\cline { 2 - 6 } & Mean & S.D. & Mean & S.D. & & \\
\hline Hindu & 26.86 & 12.56 & 6.822 & 5.982 & 9.549 & $<0.05(\mathrm{~s})$ \\
\hline Muslim & 32 & 5.033 & 6.8 & 7.259 & 5.210 & $<0.05(\mathrm{~s})$ \\
\hline
\end{tabular}

Table 9.OAS-Domicile Sub-Group

\begin{tabular}{|c|c|c|c|c|c|c|}
\hline \multirow{2}{*}{ Domicile } & \multicolumn{2}{|c|}{ Study Group } & \multicolumn{2}{c|}{ Control Group } & \multirow{2}{*}{ 't'-value } & \multirow{2}{*}{ p-value } \\
\cline { 2 - 6 } & Mean & S.D. & Mean & S.D. & & \\
\hline Rural & 26.1 & 9.677 & 5.818 & 5.618 & 5.798 & $<0.05(\mathrm{~s})$ \\
\hline Urban & 27.32 & 13.076 & 6.846 & 6.01 & 8.978 & $<0.05(\mathrm{~s})$ \\
\hline
\end{tabular}


Table 10.OAS-Occupation Sub-Group

\begin{tabular}{|c|c|c|c|c|c|c|}
\hline \multirow{2}{*}{ Occupation } & \multicolumn{2}{|c|}{ Study Group } & \multicolumn{2}{c|}{ Control Group } & \multirow{2}{*}{ 't'-value } & \multirow{2}{*}{ p-value } \\
\cline { 2 - 5 } & Mean & S.D. & Mean & S.D. & & \\
\hline Business & 36.4 & 3.91 & 11.142 & 5.335 & 9.46 & $<0.05(\mathrm{~s})$ \\
\hline Labour & 33 & 2.12 & 5.8 & 4.76 & 11.66 & $<0.05(\mathrm{~s})$ \\
\hline Service & 24.857 & 10.928 & 6.5 & 5.753 & 6.77 & $<0.05(\mathrm{~s})$ \\
\hline Housewife & 22.727 & 9.79 & 4 & 5.074 & 5.50 & $<0.05(\mathrm{~s})$ \\
\hline Student & 36.4 & 22.85 & 7 & 8.71 & 2.716 & $<0.05(\mathrm{~s})$ \\
\hline Professionals & 17.666 & 13.868 & 5.333 & 2.081 & 1.523 & $>0.05$ (NS) \\
\hline
\end{tabular}

Table I I.OAS-Educational Sub-Group

\begin{tabular}{|c|c|c|c|c|c|c|}
\hline \multirow{2}{*}{$\begin{array}{c}\text { Educational } \\
\text { Subgroup }\end{array}$} & \multicolumn{2}{|c|}{ Study Group } & \multicolumn{2}{c|}{ Control Group } & \multirow{2}{*}{ 't'-value } & \multirow{2}{*}{ p-value } \\
\cline { 2 - 5 } & Mean & S.D. & Mean & S.D. & & \\
\hline High school or below & 31.928 & 7.07 & 7.285 & 5.383 & 10.369 & $<0.05(\mathrm{~s})$ \\
\hline Graduation & 25.722 & 9.504 & 8.722 & 6.095 & 6.387 & $<0.05(\mathrm{~s})$ \\
\hline Postgraduation & 24.666 & 16.92 & 4 & 5.32 & 4.941 & $<0.05(\mathrm{~s})$ \\
\hline
\end{tabular}

There was inverse correlation between depression BDI scores and social comparison rating scores for study group.

\section{Discussion}

Humans are motivated to gain and maintain status, and be accepted by others, via efforts to create positive images of the self in the eyes of others. In this context shame relates to (failed) efforts to control the image individuals wish to create in the minds of others and fear of the response individuals are likely to elicit. The key aspect of shame therefore is that it alerts the self and others to actual or possible detrimental changes in status (devaluations) with the possible consequences of attack, rejection or disengagement from others. ${ }^{25}$

There is now considerable evidence that in many depressed states people see themselves as inferior and of low rank compared to those around them, ${ }^{19,24,26}$ are shame prone with low self-esteem which Gilbert referred to as "involuntary subordinate self-perception". ${ }^{4}$

In a study of 265 undergraduates Tangney ${ }^{27}$ concluded that shame was consistently positively correlated with the broad range of symptom checklist-90 symptoms ${ }^{28}$ e.g. depression, anxiety, somatization, obsessive-compulsive symptoms, paranoid ideation, psychoticism.

Shreve concluded that shame proneness may also increase the risk of suicide and was a factor which differentiated suicidal and non-suicidal individuals. ${ }^{29}$

In current study it has been established that phenomenon of shame is present in depressives in comparison to control group as there was statistically significant difference in mean OAS scores between both the groups, also positive correlation was found between depression BDI scores and OAS scores for study group ( $r=+0.7033)$. This was in accordance with study of Allan, Gilbert and Goss (1994). ${ }^{30}$ In their study BDI scores were positively and significantly correlated with OAS scores at $r=0.73$.

Analysis of significance of shame measures in depression across various socio-demographic variables was found to be statistically significant from control group. The difference between scores in study and control group in all age subgroup was statistically significant, but scores were highest in the age group of 31-45 years in depressed subjects which may be due to a greater tendency of selfevaluation in this age group. In sex subgroup higher scores in males attributed to their more self-analysing attitude than females.

In occupational subgroup highest scorer were Labour class, the reason may be that self-cognition in the labourers locate themselves in a low status position and shame has been linked indirectly with loss of social rank and status.

In current study, there was an inverse correlation between depression BDI scores and social comparison rating scores for study group at $r=-0.2726$ this means that increase in the severity of depression is associated with more negative social comparison. This is in accordance with study results shown by Allan and Gilbert (1995). ${ }^{24}$ In their study they found correlation value between $\mathrm{BDI}$ and social comparison $r=-0.47$.

Swallow and Kuiper propose that, under certain conditions, social comparison can operate as a significant precursor to the negative self-evaluation characteristic of depression. In individuals, who are already depressed, they propose that 
social comparison processes can function to help maintain this negative self-evaluation. ${ }^{19}$

\section{Conclusion}

It is suggested that shame and depression are related to defensive submissive strategies when individuals find themselves placed in unwanted low status/ rank positions.

A social comparison perspective may help to shed light on a number of different symptoms of depression. The social withdrawal and self-imposed isolation which characterize depression can be readily understood in the context of a social comparison perspective.

The present study has explored the phenomena of shame and social comparison in depressive disorders and found a strong positive correlation between shame and depression and an inverse correlation between social comparison and depression. It was evident on all socio-demographic variables. With increasing severity of depression person ranks himself/ herself low in various social dimensions.

The phenomena of shame and social comparison and their association with psychopathology especially with depression has been studied extensively in western countries but there is a dearth of research on this subject in Indian setting.

Shame and social comparison are found to be important variables in the phenomenology of depression. However, further research is needed to substantiate the findings of current study in Indian depressives.

\section{Source of Funding: None \\ Conflict of Interest: None \\ References}

1. Lewis HB. Shame and Guilt in Neurosis. Psychoanal Rev 1971; 58(3): 419-438.

2. Lewis HB. Introduction: Shame-the "sleeper" in psychopathology. In Lewis, H.B. (Ed.), The role of shame in symptom formation: Lawrence Erlbaum Associates, Inc. 1987; 29-50.

3. Lewis HB. The role of shame in depression. In Rutter, M.,Izard, C.E. \& Read, P.B. (eds), Depression in young people: developmental and clinical perspectives. New York: Guilford Press. 1986.

4. Gilbert P. Depression: The evolution of powerlessness. Guilford Press. 1992.

5. Gilbert P, Pehl J, Allan S. The phenomenology of shame and guilt: An empirical investigation. British Journal of Medical Psychology 1994; 67(1): 23-36.

6. Tracy JL, Robins RW. Putting the Self into Self-Conscious Emotions: A Theoretical Model. Psychological Inquiry 2004; 15(2): 103-125.

7. Tangney JP, Miller RS, Flicker L, Barlow DH. Are shame, guilt, and embarrassment distinct emotions? Journal of
Personality and Social Psychology 1996; 70(6): 1256 1269.

8. Gilbert P. What is shame? Some core issues and controversies. In P. Gilbert \& B. Andrews (Eds.), Series in affective science. Shame: Interpersonal behaviour, psychopathology, and culture. Oxford University Press. 1998; 3-38.

9. Smith RL. The relative proneness to shame or guilt as an indicator of defensive style. Unpublished doctoral dissertation, Northwestern University, 1972.

10. Izard CE. Patterns of emotions: A new analysis of anxiety and depression. San Diego, CA: Academic Press. 1972.

11. Cook DR. Shame, attachment and addictions: Implications for family therapists. Contemp Fam Ther 1991; 13: 405-419.

12. Cook DR. The Internalized Shame Scale Manual. Menomonie. WI: Channel Press. (Available from author, Rt. 7, Box 270a, Menomonie, WI 54751, U.S.A.). 1993.

13. Hoblitzelle W. Differentiating and measuring shame and guilt: The relation between shame and depression. In $\mathrm{H}$. B. Lewis (Ed.), The role of shame in symptom formation. Lawrence Erlbaum Associates, Inc. 1987; 207-235.

14. Tangney JP, Wagner P, Fletcher C, Gramzow R. Shamed into anger? The relation of shame and guilt to anger and self-reported aggression. Journal of Personality and Social Psychology 1992; 62: 669-675.

15. Tangney JP, Wagner P, Gramzow R. Proneness to shame, proneness to guilt, and psychopathology. Journal of Abnormal Psychology 1992; 101: 469-478.

16. Jackson SW. Melancholia and Depression: From Hippocratic Times to Modern Times. New Heaven: Yale University Press. 1986.

17. Festinger L. A theory of social comparison processes. Human Relations 1954; 7: 117-140.

18. Price JS. Alternative channels for negotiating asymmetry in social relationships. In M.R.A. Chance (Ed.), Social Fabrics of the Mind. Hove, Sussex: Erlbaum. 1988.

19. Swallow SR, Kuiper NA. Social comparison and negative self-evaluations: An application to depression. Clinical Psychology Review 1988; 8(1): 55-76.

20. Carver CS, Ganellen RJ. Depression and components of self-punitiveness: High standards, self-criticism, and overgeneralization. Journal of Abnormal Psychology 1983; 92(3): 330-337.

21. Beck AT, Rush AJ, Shaw BF, Emery G. Cognitive therapy of depression. New York: Guilford Press. 1979.

22. Beck AT, Steer RA, Garbin HG. Psychometric properties of the Beck Depression Inventory: Twenty-five years of evaluation. Clinical Psychology Review 1988; 8: 77-100.

23. Goss K, Gilbert P, Allan S. An exploration of shame measures: I. The Other As Shamer Scale. Personality and Individual Differences 1994; 17(5): 713-717.

24. Allan S, Gilbert P. A social comparison scale: Psychometric 
properties and relationship to psychopathology. Personality and Individual Differences 1995; 19(3): 293-299.

25. Leary MR, Kowalski RM. Impression management: A literature review and two-component model. Psychological Bulletin 1990; 107(1): 34-47.

26. Gilbert P, Allan S, Trent DR. Involuntary subordination or dependency as key dimensions of depressive vulnerability? J Clin Psychol 1995; 51(6): 740-752.

27. Tangney JP. The mixed legacy of the superego: Adaptive and maladaptive aspects of shame and guilt. In J. M. Masling \& R. F. Bornstein (Eds.), Empirical perspectives on object relations theory (1-28). American Psychological Association. 1994

28. Derogatis LR, Lipman RS, Covi L. SCL-90: An outpatient psychiatric rating scale-preliminary report. Psychopharmacology Bulletin 1973; 9: 13-28.

29. Shreve BW. Constructing a measure of shameproneness and its relation to treatment outcome for hospitalised individuals. Unpublished doctoral dissertation, University of Tennessee, Knoxville. 1987.

30. Allan S, Gilbert P, Goss K. An exploration of shame measures: II. Psychopathology. Personality and Individual Differences 1994; 17(5): 719-722. 